\title{
Fat, polyphenol and minerals estimate in exotic accessions of cocoa (Theobroma cacao L.)
}

\author{
S. A. Veeresh ${ }^{1}$, J. S. Minimol*, B. Suma, M. R. Athira and K.S. Shilpa \\ Cocoa Research Centre, Kerala Agricultural University, Vellanikkara, Thrissur (Kerala) India \\ (Email: minimol.js@kau.in; minimoljs@gmail.com; suma.b@kau.in; athiramr241@gmail.com; shilpakstrk@gmail.com)
}

\begin{abstract}
Cocoa is earmarked for its products, made out of fermented and dried beans. Cocoa butter is the major ingredient in chocolate which help us to enjoy the melted chocolate in the mouth. Due to its elevated anti-oxidant property it is used many pharmaceutical and cosmetic products. Fat content above 45 per cent can be considered as a desirable trait and the accessions NA 149 (50.38\%), PNG 418 (50.21\%) etc. were with high fat content in beans can be selected for further breeding programme. Polyphenols comprise of 12-18 per cent of the total bean weight and it mainly influences the chocolate colour. It is also reported to have high anti-oxidant property. The highest total phenol content was observed in genotypes ICS 41 (11.81\%) followed by CRU $12(11.60 \%)$ and IMC 20 (11.27\%). Cocoa beverage is considered to be a good source of calcium, potassium and sodium and is very much desirable for health. Genotype JA $10 / 12$ showed highest sodium content of $1.98 \mathrm{mg} / 100 \mathrm{~g}$. MATINA $1 / 7$ (2002.07mg/ $100 \mathrm{~g}$ ) expressed highest potassium content and calcium content was highest for the accession CRU $12(329 \mathrm{mg} / 100 \mathrm{~g})$. Cluster analysis was carried out by using $\mathrm{D}^{2}$ statistics. All the accession was highly variable and even at 25 per cent similarity level, majority of accessions found to remain as independent units. Breeding for quality is the current trend in cocoa breeding. Hence, the wide variability observed among the exotic genotypes can be exploited for developing superior varieties with improved biochemical properties.
\end{abstract}

Key Words : Cocoa, Theobroma cacao L., Cocoa butter, Polyphenol, Mineral content, Biochemical

View Point Article : Veeresh, S.A., Minimol, J.S., Suma, B., Athira, M.R. and Shilpa, K.S. (2020). Fat, polyphenol and minerals estimate in exotic accessions of cocoa (Theobroma cacao L.). Internat. J. agric. Sci., 16 (1) : 11-16, DOI:10.15740/HAS/IJAS/16.1/11-16. Copyright@2020: Hind Agri-Horticultural Society.

Article History : Received : 25.10.2019; Revised : 02.11.2019; Accepted : 03.12.2019

\footnotetext{
* Author for correspondence:

'Department of Plant Breeding and Genetics, College of Horticulture (K.A.U.), Vellanikkara (Kerala) India (veereshsakki@gmail.com)
} 